\title{
An Assessment of the Diversity in Scenario-based Tsunami Forecasts for the Indian Ocean
}

Diana J. M. Greenslade ${ }^{1}$, Alessandro Annunziato ${ }^{2}$, Andrey Babeyko ${ }^{3}$, David Burbidge ${ }^{4}$, Enrico Ellguth $^{3}$, Nick Horspool ${ }^{4}$, T. Srinivasa Kumar ${ }^{5}$, Ch. Patanjali Kumar ${ }^{5}$, Chris Moore ${ }^{6}$, Natalja Rakowsky $^{7}$, Torsten Riedlinger ${ }^{8}$, Anat Ruangrassamee ${ }^{9}$, Patchanok Srivihok ${ }^{10}$, Vasily V. Titov ${ }^{6}$

${ }^{1}$ Bureau of Meteorology, Melbourne, AUSTRALIA.

${ }^{2}$ European Commission Joint Research Centre, Ispra, ITALY

${ }^{3}$ GFZ, Potsdam, GERMANY

${ }^{4}$ Geoscience Australia, Canberra, AUSTRALIA.

${ }^{5}$ Indian National Centre for Ocean Information Services, INDIA

${ }^{6}$ National Center for Tsunami Research, USA

${ }^{7}$ Alfred Wegener Institute, GERMANY

${ }^{8}$ German Aerospace Center, GERMANY

${ }^{9}$ Chulalongkorn University, THAILAND

${ }^{10}$ Regional Integrated Multi-hazard Early Warning System, THAILAND

\section{Corresponding Author:}

Dr Diana Greenslade

Centre for Australian Weather and Climate Research

Australian Bureau of Meteorology

GPO Box 1289

Melbourne VIC 3001 Australia

Phone: 61-3-9669 4124

Fax: 61-3-9669 4660

e-mail: d.greenslade@,bom.gov.au 


\begin{abstract}
This work examines the extent to which tsunami forecasts from different numerical forecast systems might be expected to differ under real-time conditions. This is done through comparing tsunami amplitudes from a number of existing tsunami scenario databases for eight different hypothetical tsunami events within the Indian Ocean. Forecasts of maximum tsunami amplitude are examined at ten output points distributed throughout the Indian Ocean at a range of depths. The results show that there is considerable variability in the forecasts and on average, the standard deviation of the maximum amplitudes is approximately $62 \%$ of the mean value. It is also shown that a significant portion of this diversity can be attributed to the different lengths of the scenario time series. These results have implications for the interoperability of Regional Tsunami Service Providers in the Indian Ocean.
\end{abstract}

Keywords: tsunami, tsunami forecast, Indian Ocean, intercomparison, real-time 


\section{Introduction}

The Indian Ocean Tsunami Warning and mitigation System (IOTWS) has developed rapidly since its establishment after the Indian Ocean Tsunami of 2004. One of the major elements of the IOTWS is the concept of a Regional Tsunami Service Provider (RTSP). An RTSP is a centre that provides an advisory tsunami forecast service to one or more National Tsunami Warning Centres (NTWC). The RTSPs have a number of requirements that they need to meet (IOTWS, 2009), one of which is that they must have access to numerical model-based tsunami forecasts and the numerical model used should be appropriately benchmarked and validated (IOTWS, 2008; Synolakis et al., 2008). Another important aspect of the RTSP concept is that the service and products provided by each RTSP should be "inter-operable". In this context, "inter-operable" means that the products to be exchanged are in the same format and relate to the same physical parameters.

The aim of the present work is to determine the extent to which event-specific tsunami amplitude forecasts from different numerical forecast systems differ, and therefore, how the relevant products from RTSPs might differ. This is done by comparing tsunami amplitudes for a number of different hypothetical tsunami events within the Indian Ocean, from a number of different tsunami scenario databases.

\section{Model Forecast Databases}

At time of writing there are three centres within the IOTWS exchanging numerical forecasts of tsunami amplitude in real-time during events. These centres are the Joint Australian Tsunami Warning Centre (JATWC), the German-Indonesian Tsunami Early Warning System (GITEWS) and the Indian Tsunami Early Warning Centre (ITEWC). Comparison between these three systems will be essential for an understanding of the implications of the IOTWS's RTSP concept. There are several other international systems that are able to provide tsunami amplitude estimates within the Indian Ocean and so in the present work, the study is extended to include a number of other existing data sets. This more comprehensive dataset will provide an improved assessment of the potential diversity in the forecasts. 
Therefore, in the present work, forecasts from eight separate tsunami forecast systems are considered. It is emphasized that not all of these forecast systems are existing or proposed IOTWS RTSPs. Indeed, not all of them can truly be described as "forecast" systems as they are predominantly used for applications such as risk assessment and research. However, each of these systems is able to produce an estimate of tsunami amplitude at a specific location, when given details of a potentially tsunamigenic earthquake within the Indian Ocean. The eight forecast systems considered here are described in the remainder of this section, with the three existing RTSPs described first.

\subsection{Joint Australian Tsunami Warning Centre (JATWC)}

Tsunami forecasts for the JATWC are based on the T2 scenario database (Greenslade et al. 2009, 2011; Simanjuntak et al. 2011). The basis for the source locations within T2 is the set of subduction zones within the Indian, Pacific and South Atlantic Oceans as defined by Bird (2003). Earthquake epicentres are defined at $100 \mathrm{~km}$ intervals along these subduction zones, resulting in a total of 522 source locations.

The T2 scenario database includes 5 earthquake magnitudes of $M_{w}=7.0,7.5,8.0,8.5$ and 9.0 at each source location. The ruptures for large earthquakes are represented as the sum of a number of smaller $100 \mathrm{~km}$ long rupture elements, each of which has their strike closely aligned with the local subduction zone. For example, for a $M_{w}=8.0$ scenario, two adjacent rupture elements are combined to create one rupture with length approximately $200 \mathrm{~km}$, width of $65 \mathrm{~km}$ and slip of $2.2 \mathrm{~m}$. Details of the rupture dimensions for each magnitude are shown in Table 1 . When all 5 magnitude scenarios are included, this results in a total of 2,069 individual scenarios in the T2 scenario database.

Table 1. Details of the initial conditions used for the scenarios in the JATWC T2 scenario database.

\begin{tabular}{|c|c|c|c|c|}
\hline Magnitude $\left(M_{w}\right)$ & $\begin{array}{c}\text { Width } \\
(W)\end{array}$ & $\begin{array}{c}\text { Number of } \\
\text { rupture } \\
\end{array}$ & $\begin{array}{c}\text { Length } \\
\text { (approx.) }(L)\end{array}$ & $\begin{array}{c}\text { Slip }\left(u_{o}\right) \\
(\mathrm{m})\end{array}$ \\
\hline $\mathbf{7 . 0}$ & 35 & 1 & 50 & 0.5 \\
\hline
\end{tabular}




\begin{tabular}{|c|c|c|c|c|}
\hline $\mathbf{7 . 5}$ & 50 & 1 & 100 & 1 \\
\hline $\mathbf{8 . 0}$ & 65 & 2 & 200 & 2.2 \\
\hline $\mathbf{8 . 5}$ & 80 & 4 & 400 & 5 \\
\hline $\mathbf{9 . 0}$ & 100 & 10 & 1000 & 8.8 \\
\hline
\end{tabular}

Sea-level for tsunamis generated by intermediate magnitude earthquakes, i.e. those with magnitudes other than 7.0, 7.5, 8.0, 8.5 and 9.0 is derived from the pre-computed scenarios by applying a scaling factor to them. This provides guidance for earthquakes with magnitudes ranging from 6.8 to 9.2 at 0.1 magnitude intervals. Details on the scaling factors can be found in Greenslade et al. (2009).

Dip values for the T2 scenarios range from a shallow $8^{\circ}$ along the Makran fault, to almost $70^{\circ}$ along the Hjort trench (south-west of New Zealand). In the locations where a dip rate has not been established a standard dip value of $25^{\circ}$ is used. The underlying bathymetry dataset used in T2 is the Naval Research Laboratory Digital Bathymetry Data Base with 2 arcmin resolution $\left(\mathrm{NRL}\right.$ DBDB2 ${ }^{1}$ ) with other bathymetries merged into it in particular regions (Mansbridge, unpublished document). All of the T2 scenarios have the same rake $\left(90^{\circ}\right)$ and depth (top of rupture $=10 \mathrm{~km}$ ) of the hypocentre.

The Okada (1985) solution is used to generate the seafloor displacement from the seismic source and the Method of Splitting Tsunamis (MOST) model (Titov and Synolakis, 1998) is used to generate the scenarios. The model simulation time for each scenario is 24 hours to ensure that reflections off underwater features or distant coasts are captured. The horizontal grid spacing for T2 is 4 arcmin and through the Courant-Friedrichs-Lewy (CFL) criterion, this imposes a limit of 12 seconds on the time step. The maximum tsunami amplitude for each scenario is calculated at each time step and only positive amplitudes are considered in the determination of maximum tsunami amplitude.

\subsection{Indian Tsunami Early Warning Centre (ITEWC)}

Tsunami forecasts from the Indian Tsunami Early Warning Centre (ITEWC) are based on an open ocean propagation scenario database of pre-run unit source scenarios covering the Makran and Sunda tsunamigenic source regions of the Indian Ocean (Nayak and Kumar, 2008). Based on

${ }^{1} \mathrm{http}: / /$ www7320.nrlssc.navy.mil/DBDB2_WWW/NRLCOM_dbdb2.html 
historical earthquake and tsunami data, about 1,000 simulation points (i.e. synthetic epicenters) are selected along the two subduction zones with a separation of $100 \mathrm{~km}$ along the trench and 50 $\mathrm{km}$ across the trench. Fault geometry parameters have been carefully selected based on sensitivity studies. The strike angle is assigned according to historical earthquakes which actually occurred near the simulation point and triggered tsunamis in the past. In cases where the parameters of the historical earthquakes are uncertain, the strike angle is assigned in such a way that it will represent the worst case, i.e. parallel to the coast or the nearby trench. The dip angle and hypocentral depth are assigned so that the subducting zone is well represented by the simulation points and the rake angle is defined to be 90 degrees. A fault length of $100 \mathrm{~km}$, width of $50 \mathrm{~km}$ and displacement (slip) of $1 \mathrm{~m}$ defines each unit source which is equivalent to a magnitude 7.5 earthquake.

During any earthquake event depending on earthquake's location and magnitude, a combination of basic unit source scenarios are selected from the scenario database and scaled up or down using a slip parameter derived from scaling relations for any depth. This eliminates the need for a large database of individual matching scenarios. Results for earthquakes with magnitudes ranging from 6.5 to 9.5 for any depth, at 0.1 magnitude intervals can be obtained from the set of selected unit source scenarios by applying a scaling factor to the scenario results.

The unit source scenario database has been developed using the finite difference code TUNAMI N2 (Imamura, 2006). Studies have been carried out to validate the model results with the December 26, 2004 Sumatra earthquake (Murthy et al. 2005; Usha et al. 2009). The model domain covers $30^{\circ} \mathrm{N}$ to $40^{\circ} \mathrm{S}$ latitude and $30^{\circ} \mathrm{E}$ to $130^{\circ} \mathrm{E}$ longitude with a grid spacing of 0.0450 degrees (approximately $5 \mathrm{~km}$ ). According to the CFL criterion, a model time step of $5 \mathrm{sec}$ is used, to ensure stability. Each scenario covers the entire Indian Ocean domain with 15 hours of simulation time. Tsunami profiles are saved at Coastal Forecast Points (CFPs) for each scenario for the 15 hours of computation at 15 second intervals. The CFPs are selected at $30 \mathrm{~m}$ depth assuming that until such depth, the computation is linear. About 1,800 CFPs are selected for the tsunami domain separated by $\sim 50 \mathrm{~km}$ covering all Indian Ocean rim countries (Nayak and Kumar, 2008). Arrival times and wave heights at specific coastal locations for each scenario are stored in a database. Travel times to the coast are calculated by considering the speed of the wave at different depths $(30 \mathrm{~m}, 20 \mathrm{~m}, 15 \mathrm{~m}$ and $10 \mathrm{~m})$. The distance to the coast is divided by the 
average speed to get the travel times at the coast. Tsunami wave heights at the coast are calculated using Greens Law:

$$
\frac{h_{s}}{h_{d}}=\left(\frac{H_{d}}{H_{s}}\right)^{\frac{1}{4}}
$$

where $h_{s}$ and $h_{d}$ are the wave heights in shallow and deep water respectively, and $H_{s}$ and $H_{d}$ are the depths of the shallow and deep water, respectively. In this case, the deep water depth is $30 \mathrm{~m}$.

In addition to the unit source scenario database, ITEWC also has an earlier version of the scenario database (Nayak and Kumar, 2008) with scenarios at discrete earthquake magnitudes $(6.5,7.0,7.5,8.0,8.5,9.0 \& 9.5)$ and depths $(10,20,33,40,60,80 \& 100 \mathrm{~km})$ at every simulation point, comprising about 50,000 scenarios in number.

\subsection{German-Indonesian Tsunami Early Warning System (GITEWS) - Indian Ocean Tsunami Information Center (IOTIC)}

The Indian Ocean wide tsunami warning from GITEWS is based on a repository of tsunamis generated by prototypic earthquakes with magnitude decreasing from 9.0 in steps of 0.2 down to a lower bound for each epicenter, such that the lowest regarded magnitude provides no threat to any country except Indonesia. For Indonesia itself, the regional watch system InaTEWS covers the local tsunami risk.

Initial conditions along the Sunda trench were computed using the GITEWS source-simulation tool RuptGen (Babeyko et al. 2010). RuptGen was designed for near-field tsunami forecasting in Indonesia and supports (near-) real time GPS-based slip inversion (Sobolev et al. 2007). The curved 3D plate interface (Gudmundsson and Sambridge, 1998) is discretized into 150x25 rectangular patches each being about $40 \mathrm{~km}$ long and $15 \mathrm{~km}$ wide and ranging from the trench down to $100 \mathrm{~km}$ depth. Dipping angles of individual patches vary from $8^{\circ}$ to $60^{\circ}$ in accordance with the 3D plate interface geometry. For each patch, three components of surface deformation in response to unit dip- and strike-slip were precomputed and stored in a databank of Green's functions. Surface deformation was computed in 1D layered earth model approximation (IASP91) using the EDGRN/EDCMP software (Wang et al. 2003). 
Given an earthquake magnitude and location, a simplified finite fault model is calculated and projected onto the 3D plate interface. In this model, rupture dimensions follow some scaling relations (in this case, Wells and Coppersmith, 1994) and the slip distribution obeys a dipdirected smooth-closure condition (Geist and Dmowska, 1999). Note that the non-uniform slip distribution accounts for higher initial uplift compared to the classical Okada's fault, which results in generally higher maximal wave amplitude, especially in the near-field. After establishing the slip distribution, final co-seismic surface deformation is computed by linear superposition of Green's function patches. Optionally, shear modulus may be considered as depth-dependent (Bilek and Lay, 1999) which would facilitate larger slip in the vicinity of the trench thus accounting for so-called 'tsunami earthquakes' (not used in this study).

For the sources in the Makran region the classical single Okada-fault model is employed, with uniform slip and rupture dimensions computed from the scaling law with $\mathrm{L}=2 \mathrm{~W}$.

Tsunami generation, propagation and inundation is calculated with the finite element shallow water model TsunAWI (Harig et al. 2008). The unstructured computational grid consists of triangles with a minimum edge length of $200 \mathrm{~m}$ in coastal regions, a maximum of $25 \mathrm{~km}$ in the deep ocean, and 6.6 million nodes in total. The resolution varies smoothly between coarsely resolved deep water and finely resolved shallow regions, such that the computational grid provides a good balance between computational cost and resolution of important bathymetric structures. It should be noted that realistic inundation results would require an even higher resolution of the topography. However, the simulation of inundation avoids unnatural wave reflections at the coast, thus making the results in shallow water more reliable.

During a 24 hour model simulation with a time step of 2-3s, the sea surface height is written once per minute at 25,000 points evenly distributed at $10 \mathrm{~m}$ and $50 \mathrm{~m}$ depth along the coastlines of Africa, Asia and Australia. Furthermore, the maximum wave height over all time steps and the arrival time are captured at the POIs and on all nodes of the computational grid with a water depth of $50 \mathrm{~m}$ or more.

\subsection{Regional Integrated Multi-Hazard Early Warning System (RIMES)}


RIMES have implemented TUNAMI models in developing the tsunami forecast system (IUGG/IOC TIME Project, 1997). The linear TUNAMI model in a spherical coordinate system (TUNAMI-F1) is used to determine tsunami amplitudes and fluxes in the open ocean. Dispersion is taken into account by considering the Imamura Number. The TUNAMI model with nested grids in a Cartesian coordinate system (TUNAMI-N2) is implemented for near-shore areas where nonlinearity is significant. The two models are nested to allow computation of tsunami propagation and tsunami inundation simultaneously. The model setup has been compared to tsunami observation from the 2004 Indian Ocean Tsunami with good agreement (Ruangrassamee and Saelem, 2009).

RIMES have developed three sets of unit source databases for tsunami forecasts:

1) Database for fast tsunami warning. This database includes tsunami amplitudes over a large area computed by the TUNAMI-F1 model with a grid size of 2 arc-minutes. This database is used for comparison in the research.

2) Database for inundation modeling. This database comprises tsunami fluxes computed by the TUNAMI-F1 model with a grid size of 2 arc-minutes. The fluxes are input at boundary of a sub-region as forced boundaries to the TUNAMI-N2 model. There are three sub-regions in the TUNAMI-N2 model with the smallest resolution of about $50 \mathrm{~m}$.

3) Database for inverse analysis of tidal gauge data. This database was developed using the nested TUNAMI-F1 and TUNAMI-N2 models. The resolutions are 2 arc-minutes and 15 arc-seconds in the TUNAMI-F1 and TUNAMI-N2 models, respectively.

Unit sources used in developing the database are defined with length $=100 \mathrm{~km}$, width $=50 \mathrm{~km}$, $\operatorname{slip}=1 \mathrm{~m}$ and rake $=90^{\circ}$.

There are three main subduction zones in the region under RIMES's tsunami watch: Sunda, Western Philippines, and Makran subduction zones. The appropriate fault parameters were determined from previous studies on subduction zones. Unit sources were aligned along fault planes with dip angles corresponding to the profiles proposed by Gudmundsson and Sambridge (1998). There are a total of 250, 51, and 22 unit sources for the Sunda, Western Philippines, and Makran subduction zones, respectively. Sea floor deformation was determined for each unit 
source using the formulation proposed by Mansinha and Smylie (1971). Tsunami propagation was performed for all 323 cases. Time histories of tsunami amplitudes at grid points were archived and then retrieved for superposition to determine tsunami amplitudes, arrival time, amplitudes at coastlines and tsunami threat levels.

\subsection{Geoscience Australia (GA)}

GA has three tsunami databases; one with output points around Australia, one covering the other countries around the Indian Ocean and one for the island nations in the southwest Pacific. These tsunami waveform databases have two main uses. They provide:

1. Tsunami waveforms for use in calculating probabilistic tsunami hazard assessments (PTHA) for points offshore the coast (e.g. Burbidge et al., 2008; Gonzales et al., 2009) and;

2. Input boundary conditions for detailed coastal inundation models

Note that the databases were not created for use in real-time forecasting of tsunamis.

Once the earthquake recurrence probabilities are known, these databases can be used to calculate hazard maps showing (for example) the maximum offshore wave height with a particular probability of being exceeded each year. These PTHAs can then be deaggregated to identify which tsunami source is responsible for most of the hazard at a particular return period for a particular point off the coast. This is useful for selecting events for inundation modelling that use the PTHA waveform database as boundary conditions.

To generate the tsunamis used in these databases the megathrust faults under consideration are sub-divided into $100 \mathrm{~km}$ by $50 \mathrm{~km}$ "sub-faults". The megathrust fault geometry (i.e. strike and location) is based on the plate model of Bird (2004) with the additional Arakan fault suggested by Cummins (2007). All of the subduction zones in Bird (2004) for the Indian, South Atlantic and Pacific Oceans are included. The dip of the megathrust at each zone is estimated from the Regional Upper Mantle (RUM) model of Gudmundsson \& Sambridge (1998) or from papers based on seismic surveys of that specific zone. There are 1,850 sub-faults in the Australia database, fewer in the other two databases. 
For each sub-fault the sea floor deformation at the surface was calculated for $1 \mathrm{~m}$ of slip with $90^{\circ}$ rake (i.e. pure thrust). This is calculated by assuming the fault can be represented by a dislocation in a layered elastic medium. The layered elastic properties of the crust were based on CRUST2.0 (Bassin et al. 2000) and Kopp and Kukowski (2003). The code used to calculate the sea floor deformation is described in more detail in Wang et al. (2006).

The tsunami from each sub-fault is then numerically modelled to the coast. To save disk space, only those points near the $100 \mathrm{~m}$ water depth contour are saved. For example, in the Australian database the waveforms from each sub-fault are only saved at 3,852 points around the Australian coast.

The tsunami propagation for each sub-fault was modelled using a staggered grid finite difference scheme to solve the linear shallow water wave equations. The code is based on the one used in Satake (1995) but rewritten in C and with other enhancements (e.g. nested grids). The code has been validated for deep ocean propagation (Thio et al. 2007). The time step was set to be $2.5 \mathrm{~s}$ and the waveform data is stored once the tsunami reaches a particular point off the coast. Model simulation time depends on how long it takes for the tsunami from that sub-fault to reach the furthest output point so it varies from sub-fault to sub-fault.

The bathymetry used in the propagation modelling is a merged grid based on a combination of the US Naval Laboratory's Digital Bathymetric Data Base (DBDB2) and GA's own bathymetry data off the coast of Australia. The combined grid is resampled to a regular grid of points spaced one to two arc minutes apart depending on the database.

To calculate a tsunami from an arbitrary sized earthquake on one of the megathrusts, the subfaults within the rupture zone of an earthquake are determined. The geometry of the rupture area is calculated using the Wells and Coppersmith (1994) relations. The tsunami waveforms for each sub-fault within the rupture area are then multiplied by the slip of the earthquake and summed together. In other words, a Green's function summation approximation is used to generate the final wave. Using Green's functions means that the tsunami waveform can be found at any location near the coast very quickly, so long as the earthquake can be approximated by the sub- 
faults stored in the database. Green's function summation works in this case because the tsunami propagation in deep water is approximately linear (Satake, 1995).

For a typical PTHA, many tens of thousands of tsunami are calculated in this way for a range of earthquakes between magnitude 7.0 and a zone specific earthquake maximum magnitude. The probability for each event for a given PTHA is calculated using a logic tree like that described in Burbidge et al. (2008) or Thio et al. (2007) and varies from assessment to assessment.

\subsection{European Commission Joint Research Centre (JRC)}

The Joint Research Centre of the European Commission has been operating the Global Disasters Alerts and Coordination System $\left(\mathrm{GDACS}^{2}\right)$ since 2003. This system, jointly developed by the European Commission and the United Nations Office for Coordination of Humanitarian Affairs (UN-OCHA), combines existing web-based disaster information management systems with the aim to alert the international community in case of major sudden-onset disasters and to facilitate the coordination of international response during the relief phase of the disaster. When new natural disaster events occur automatic analysis reports are created and sent to the users by mail, fax or sms. When a potential tsunami is identified, the system relies on a global tsunami scenario database, containing 136,000 different scenarios with magnitudes ranging from 6.5 to 9.5 at intervals of 0.25 (Annunziato, 2007). This database allows estimation of the maximum expected height for each event in real-time and this height is used to estimate the alerting level in the GDACS system. At the same time, when a new event is identified, an online calculation is also launched with the reported latitude, longitude, magnitude and depth in order to have a better evaluation of the event. This online calculation is then published automatically on the GDACS website but does not contribute to the estimation of the alerting level.

The results used in the present study are drawn from the JRC scenario database. All the calculations are performed using the JRC model which assumes an initial fault form with a $\cos ^{2}(x)$ shape which may be regarded as an Okada model with zero focal depth. As such, it is a rather conservative model corresponding to a shallow event. In order to account for earthquakes

\footnotetext{
${ }^{2}$ http://www.gdacs.org
} 
of different depths a focal depth scaling factor is used, which represents the maximum height ratio with an equivalent Okada model at a variable depth.

In general, the time period of the calculation increases with the magnitude: the smallest events are simulated for only 1 hour. However, in the present study, all the calculations have been extended to 12 hours to allow comparison with other simulations.

\subsection{German Research Centre for Earth Sciences (GFZ)}

Rapidly increasing computing power and the appearance of novel high-performance computing technologies like Graphics Processing Unit (GPU) computing bring new alternatives to the classical tsunami forecasting technique based on precomputed scenarios. The tsunami simulation team in GFZ is developing time-efficient on-the-fly tools for operational tsunami forecasting. Supra-real-time tsunami simulations (i.e. computation of a full tsunami propagation forecast onthe-fly, in a time feasible for the early warning) have some advantages as well as disadvantages compared to the traditional database approach. The main advantage is the absence of a scenariodatabase which requires significant resources, both hardware and human (for managing, upgrading, etc.). Another advantage is that there is no need to interpolate between pre-computed magnitudes and locations.

On-the-fly simulations cannot compete with pre-computed models in terms of near-shore resolution and degree of approximation. The present simulations were carried out with the tsunami propagation code EasyWave whose numerical scheme basically follows the TUNAMIF1 algorithm (TIME Project, 1997) and is a leap-frog explicit time-stepping scheme on a staggered finite-difference grid. EasyWave solves the long-wave equations including the Coriolis term in spherical coordinates. Boundary conditions presume full reflection along shorelines.

Linear approximation and relatively coarse grid resolution limit the simulation accuracy near the shoreline. However (i) available bathymetry resolution is usually limited except for some dedicated areas near large cities, (ii) most forecast points in the present study are off-shore and (iii) the largest uncertainty in early warning comes from the uncertainty in source parameters, so 
on-the-fly tsunami forecasting provides a reasonable alternative to the traditional scenariodatabase approach.

The source modeling is the same as that described in Section 2.3 above. For the present study, wave propagation was solved on a 2 arc minute ETOPO2v2 bathymetric grid consisting of 2700 X 1950 (> 5 million) nodes. Each scenario was integrated for 10 hours of simulation time. Total scenario computation time on a QuadCore Intel Xeon PC was about 6'30". A trial GPU-version of EasyWave was able to compute a 10-hour forecast in about 1 minute.

It should be noted that both the tsunami generation and propagation codes are still under development. The results presented in this work should be considered as preliminary.

\subsection{US National Oceanic and Atmospheric Administration (NOAA) Center for Tsunami Research (NCTR)}

Tsunami forecasts for the United States generated by their Short-term Inundation Forecast for Tsunamis (SIFT) forecast system use a two-step process in which (1) offshore wave measurements are compared with pre-computed model runs in a propagation database, and combined and scaled to fit the measurements, and (2) the resulting scenarios are used as boundary condition forcing for small-scale nonlinear inundation model runs of individual communities (Gica et al. 2008; Wei et al., 2008; Tang et al., 2012).

The propagation database runs are initiated by calculating initial surface displacement using a deformation model with input parameters from taken from fault plane estimates of epicenter, depth, and dip, rake and strike angles. For each run, the strike angle is aligned along the known fault zones in the Pacific, Atlantic, and Indian oceans, and divides the faults into $100 \mathrm{~km}$ by 50 $\mathrm{km}$ rectangular fault planes. These model runs, known as "unit sources", use a slip value, $u_{0}$, of 1 $\mathrm{m}$, giving a moment magnitude, $M_{w}$, of 7.5. All scenarios are given a rake value of $90^{\circ}$ based on results of a sensitivity study by Gica et al. (2008). While the value of dip varies from $0^{\circ}$ to $80^{\circ}$, the vast majority of scenarios fall between $10^{\circ}$ and $30^{\circ}$ globally. Ranges of seismic parameters for the scenarios are shown in Table 2. 
Using these parameters, the Okada (1985) model is used to calculate the deformation due to shear and tensile faults in an elastic half-space due to a finite rectangular source. This deformation is taken as the initial condition for the Method of Splitting Tsunamis (MOST) model (Titov and Synolakis, 1998).

Table 2. Seismic parameter ranges for propagation database scenarios used in the US NOAA forecast system.

\begin{tabular}{c|ccccccc}
\hline $\begin{array}{c}\text { Ocean } \\
\text { Basin }\end{array}$ & $\begin{array}{c}\text { Length } \\
(\mathbf{k m})\end{array}$ & $\begin{array}{c}\text { Width } \\
(\mathrm{km})\end{array}$ & $\begin{array}{c}\text { Slip, } \boldsymbol{u}_{\mathrm{o}} \\
(\mathrm{m})\end{array}$ & $\begin{array}{c}\text { Depth } \\
(\mathrm{km})\end{array}$ & $\begin{array}{c}\text { Strike } \\
(\text { degrees})\end{array}$ & $\begin{array}{c}\text { Dip } \\
\text { (degrees) }\end{array}$ & $\begin{array}{c}\text { Rake } \\
\text { (degrees) }\end{array}$ \\
\hline Pacific & 100 & 50 & 1.0 & $1.4-$ & $0^{\circ}-360^{\circ}$ & $0.0^{\circ}-80.0^{\circ}$ & $90^{\circ}$ \\
& & & & 131.8 & & & \\
Atlantic & 100 & 50 & 1.0 & $5.0-56.3$ & $0^{\circ}-360^{\circ}$ & $15.0^{\circ}-$ & $90^{\circ}$ \\
& & & & & & $30.0^{\circ}$ & \\
Indian & 100 & 50 & 1.0 & $5.0-57.0$ & $4.7^{\circ}-$ & $3.0^{\circ}-12.0^{\circ}$ & $90^{\circ}$ \\
& & & & & $308.9^{\circ}$ & & \\
\hline
\end{tabular}

The propagation database is comprised of MOST model runs on underlying bathymetry datasets derived from several data sources depending on the basin. The Indian Ocean grid is based on SRTM30_PLUS, with augmentation from digitized sounding data from charts of western Thailand and Sumatra. Data were re-gridded to a 4 arc-minute resolution for simulations, and stretched in latitude to preserve square grid cells, allowing maximum CFL stability criterion. The propagation runs impose reflection boundary conditions at $20 \mathrm{~m}$ water depth and do not include inundation. The simulation time step is 12 seconds for the Pacific and Indian grids, and 10 seconds for the Atlantic grid. Output is saved at 60-second temporal resolution, and 16 arcminute spatial resolution and run for 30 hours of simulation time. The database contains a total of 1,696 unit sources that can be combined to form scenarios: 1,155 in the Pacific, 214 in the Atlantic/Caribbean, and 327 in the Indian Ocean.

The U.S. SIFT forecast system uses these unit sources to create real-event scenarios by scaling time series of candidate unit sources at tsunameter locations using a least-squares methodology. The resulting scenarios are comprised of data-inverted combinations of unit source propagation 
runs, and are used to force high-resolution, nonlinear MOST inundation models run in real-time during events. Details of the forecast methodology can be found in Titov (2009).

\subsection{Summary}

An important point to note from the above descriptions is that there are numerous differences between each of these tsunami forecast systems. There are a range of numerical models used, rupture definitions, underlying bathymetry datasets, spatial resolutions, model simulation-times etc. All of these factors will contribute to diversity in the forecasts. A summary of some of the key elements for the data analysed in this work is provided in Table 3.

Table 3. A summary of some key elements of the eight forecast systems

\begin{tabular}{|c|c|c|c|c|c|}
\hline System & Technique & $\begin{array}{c}\text { Propagation } \\
\text { code }\end{array}$ & $\begin{array}{c}\text { Simulation } \\
\text { time }\end{array}$ & $\begin{array}{c}\text { Spatial } \\
\text { resolution }\end{array}$ & $\begin{array}{c}\text { Output time } \\
\text { interval }\end{array}$ \\
\hline JATWC & $\begin{array}{c}0.5 \text { interval } \mathrm{M}_{\mathrm{w}} \\
\text { with linear scaling }\end{array}$ & MOST & 24 hours & 4 arc min & $2 \mathrm{~min}$ \\
\hline ITEWC & Unit source & TUNAMI- N2 & 15 hours & 2.7 arc $\min$ & $15 \mathrm{sec}$ \\
\hline GITEWS & 0.2 interval $\mathrm{M}_{\mathrm{w}}$ & TsunAWI & 24 hours & $\begin{array}{c}200 \mathrm{~m} \text { to } 25 \\
\mathrm{~km}\end{array}$ & $1 \mathrm{~min}$ \\
\hline RIMES & Unit source & TUNAMI-F1 & 18 hours & $2 \operatorname{arc} \min$ & $6 \mathrm{sec}$ \\
\hline GA & Unit source & $\begin{array}{c}\text { Modified Satake } \\
\qquad(1995)\end{array}$ & 27 hours & $\begin{array}{l}1 \text { to } 2 \text { arc } \\
\min \end{array}$ & $0.5 \mathrm{sec}$ \\
\hline JRC & 0.25 interval $\mathrm{M}_{\mathrm{w}}$ & SWAN-JRC & 12 hours & $\begin{array}{c}\text { depends on } \\
\mathrm{M}_{\mathrm{w}}\end{array}$ & $1.8 \mathrm{~min}$ \\
\hline GFZ & On-the-fly & EasyWave & 10 hours & $2 \operatorname{arc} \min$ & $15 \mathrm{sec}$ \\
\hline NCTR & Unit source & MOST & 30 hours & $4 \operatorname{arc} \min$ & $1 \mathrm{~min}$ \\
\hline
\end{tabular}

We explicitly note also that the variety of source models should be kept in mind when comparing results from different centers. Particularly for large events, different source algorithms may result in substantially different initial conditions. For example, according to the GFZ (and GITEWS) source model, the rupture area for a $M_{w}=9.1$ event is $720 \mathrm{~km}$ long, $130 \mathrm{~km}$ wide, consists of more than 200 subfaults, has non-uniform slip distribution with maximum slip up to 27 meters and produces peak uplift of more than 8 meters. Compare these source characteristics with those of JATWC T2 scenarios (Table 1, last row). It is clear that notable variety in wave generation 
would be later translated into significant scattering among forecasts regardless of the wave propagation scheme and bathymetry used.

\section{Event Scenarios}

Eight hypothetical earthquakes, i.e. scenarios, were defined, with sources within the Indian Ocean. These are listed in Table 4 and their locations are indicated on Figure 1. The intention of the comparison performed here is to emulate the details that would be available in real-time, i.e. within approximately 15 minutes after the earthquake. Hence, only the epicentre location and magnitude of the earthquake are provided to each group. The depth of the earthquake is assumed to be $30 \mathrm{~km}$ for each scenario unless otherwise defined within the forecast system.

Table 4. Hypothetical earthquakes

\begin{tabular}{llc}
\hline Source region & \multicolumn{1}{c}{ Epicentre } & Magnitude \\
\hline Makran A & $61.6^{\circ} \mathrm{E}, 25.3^{\circ} \mathrm{N}$ & 7.3 \\
Makran B & $61.6^{\circ} \mathrm{E}, 25.3^{\circ} \mathrm{N}$ & 8.3 \\
Sunda North A & $92.2^{\circ} \mathrm{E}, 10.5^{\circ} \mathrm{N}$ & 7.5 \\
Sunda North B & $92.2^{\circ} \mathrm{E}, 10.5^{\circ} \mathrm{N}$ & 8.2 \\
Sunda Central A & $100.0^{\circ} \mathrm{E}, 3.0^{\circ} \mathrm{S}$ & 7.8 \\
Sunda Central B & $100.0^{\circ} \mathrm{E}, 3.0^{\circ} \mathrm{S}$ & 9.1 \\
Sunda South A & $116.0^{\circ} \mathrm{E}, 10.5^{\circ} \mathrm{S}$ & 8.0 \\
Sunda South B & $116.0^{\circ} \mathrm{E}, 10.5^{\circ} \mathrm{S}$ & 8.7 \\
\hline
\end{tabular}

Ten output points were also defined (see Figure 1). These are the same for each scenario and are distributed throughout the Indian Ocean at a range of depths. There is one deep water location (location 9) but most of them are in the nearshore region. This is because it is the nearshore values that are exchanged by the RTSPs and used to assess the threat level. Table 5 lists the output locations and also the depths at each of these locations for each of the forecast systems. These depths vary predominantly because each system uses a different bathymetry dataset. Furthermore, given the limited spatial resolution of the systems, not all the output points are at the precise latitudes and longitudes defined. 
Table 5. Locations and depths in metres at the output locations or nearest model grid point for each centre.

\begin{tabular}{c|cccccccccccc}
\hline Lo & Lon. & Lat. & JATW & GA & RIME & JRC & GFZ & GITEW & INCOI & NCT & mean & st \\
c & & & C & & S & & & S & S & R & & dev \\
\hline 1 & 41.40 & -1.90 & 138.0 & 75.0 & 195.0 & n/a & 61.0 & 12.1 & 85.8 & 185.9 & 107.5 & 67.7 \\
2 & 55.73 & -21.00 & 310.5 & 69.0 & 159.0 & n/a & 323.0 & 498.7 & 656.9 & 2141. & 594.1 & 710.3 \\
& & & & & & & & & & 8 & & \\
3 & 72.10 & -6.00 & 47.0 & 53.0 & 59.0 & 4.0 & 57.0 & 27.5 & 59.0 & n/a & 43.8 & 20.7 \\
4 & 74.40 & 13.30 & 49.0 & 50.0 & 47.0 & 34.0 & 45.0 & 39.4 & 48.8 & 41.6 & 44.4 & 5.6 \\
5 & 81.33 & 6.16 & 452.0 & 32.0 & 31.0 & n/a & 19.0 & 19.8 & 54.9 & 652.6 & 180.2 & 261.0 \\
6 & 91.20 & 20.50 & 69.0 & 68.0 & 85.0 & 83.0 & 83.0 & 163.2 & 84.9 & 125.0 & 95.1 & 32.6 \\
7 & 95.10 & 5.50 & 96.0 & 39.0 & 47.0 & 581.0 & 35.0 & 41.2 & 58.3 & 204.0 & 137.7 & 187.8 \\
8 & 100.7 & 3.00 & 80.0 & 74.0 & 21.0 & 66.0 & 23.0 & 52.1 & 19.8 & 39.2 & 46.9 & 24.7 \\
& 0 & & & & & & & & & & & \\
9 & 100.0 & -20.00 & $5,786.0$ & 5786. & 5749.0 & 6000. & 5784. & $5,958.0$ & 5998.9 & 6094. & $5,894$. & 132.6 \\
& 0 & & & 0 & & 0 & 0 & & & 8 & 6 & \\
10 & 113.3 & -24.80 & 27.0 & 29.0 & 9.0 & 4.0 & 8.0 & 25.0 & 7.0 & 3.8 & 14.1 & 10.9 \\
& 0 & & & & & & & & & & & \\
\hline
\end{tabular}

It can be seen that there is considerable variability in the depths of the output points between the centres. This is likely to have implications for the comparison of the amplitude values at the output locations as tsunami amplitude is strongly dependent on the water depth, particularly in the nearshore

\section{Results}

Each forecast centre provided time series of sea-level elevation for each of the scenarios. Note that not every centre was able to provide data at every output location for every scenario. For example, in some cases, the modelled scenario had a limited model simulation time and so the tsunami had not reached all output points within the modelled time.

Two examples of these time series are shown in Figure 2. The top panel is from the Sunda South B scenario at Location 9 (the deep water location) and the bottom panel is from the Sunda Central B scenario at Location 10 (offshore Western Australia). It can be seen that there are a number of similarities in these time series, and also a number of differences. Firstly, in Figure 2(a) the arrival time of the leading wave is very similar for all forecasts, with less than 15 minutes between earliest and latest arrival time. The characteristics of this leading wave are in a 
broad sense also quite similar, in that the first wave is a peak (not a trough) and the phase of the first few waves are also similar. However there is considerable variability in the amplitude of the first wave. Maximum positive values of the eight time series here are: $0.069 \mathrm{~m}, 0.072 \mathrm{~m}, 0.097 \mathrm{~m}$, $0.097 \mathrm{~m}, 0.121 \mathrm{~m}, 0.136 \mathrm{~m}, 0.189 \mathrm{~m}$ and $0.234 \mathrm{~m}$, so the highest wave is more than 3 times the size of the smallest wave. In this case, the maximum values occur at the first peak for all the forecasts, but this is not necessarily the case for all events and locations.

In the lower panel of Figure 2, the characteristics of the first wave are much less consistent than they were for the deep water location. For example, it can be seen that the arrival times of the leading wave differ by about an hour between first and last arrival. There is also considerably less consistency in the phase and frequency of the waves. However, the variability in maximum positive amplitudes is similar to that of the deep water case. The maximum positive amplitudes in this case are: $0.343 \mathrm{~m}, 0.406 \mathrm{~m}, 0.497 \mathrm{~m}, 0.427 \mathrm{~m}, 0.542 \mathrm{~m}, 0.644 \mathrm{~m}, 0.680 \mathrm{~m}$ and $0.970 \mathrm{~m}$, so the highest wave is almost 3 times the lowest wave. Note that the time series are not shown here in their entirety for clarity. Inspection of this particular time series beyond 12 hours shows that the maximum value occurs well beyond 12 hours in many cases. This is not unusual for coastal locations and is often observed in tsunami signals at tide gauges (e.g. Rabinovich and Thomson, 2007). This could be due to a number of different effects such as seiching, later reflections from distant land masses, coastally trapped waves, etc. This issue is discussed further in Section 5.

Another interesting feature of these plots is that the centre that produced the highest wave in the first example did not produce the highest wave in the second example. Similarly, centres that produced very similar leading wave amplitudes in the first example produced quite different leading waves in the second example.

As mentioned earlier, within the IOTWS, RTSPs will exchange various details of their numerical forecasts. In particular, each RTSP will assess the tsunami threat based on the value of the maximum amplitude of the time series at predetermined coastal locations (IOTWS, 2009) So here we concentrate on the maximum amplitude values only. A comparison of raw maximum amplitudes determined from each centre's entire time series at each location for the Sunda Central B scenario is shown in Figure 3. Note that the data shown here for location 10 are drawn from the time series in Figure 2(b). The top panel shows the maximum positive value, while the 
bottom panel is the maximum of the absolute value of the time series, so it includes both positive and negative amplitudes. While there are some slight differences between the top and bottom panels, the general picture is qualitatively similar. For the most part, there is considerable variability in the maximum amplitudes, as might be expected from inspection of the time series shown in Figure 2. Given the similar results between maximum positive amplitudes and maximum absolute values, from this point onwards, only positive values of the tsunami amplitudes will be considered.

It is useful to have some way of comparing the variability in the maximum amplitude values between output locations and between scenarios. It is not meaningful to compare these values directly because the mean maximum amplitudes are in some cases an order of magnitude different. This is due to due to different magnitude earthquakes and also the different distances that the tsunami has traveled between source and output location. Here, we will use the Coefficient of Variation ( $\mathrm{COV}$ ) as a broad assessment of the diversity in amplitudes:

$$
\operatorname{CoV}=\frac{\sigma}{\mu}
$$

where $\sigma$ is the standard deviation of the amplitudes from all centres at a single location for a single hypothetical event and $\mu$ is the mean of those values. This will provide an assessment of how diverse the amplitude forecasts are for each case. In calculating values of the CoV, only maximum amplitude values that are greater than $1 \mathrm{~mm}$ are used.

A summary of the $\mathrm{CoV}$ for all the data is shown in Figure 4. It can be seen that the $\mathrm{CoV}$ ranges from approximately 0.28 to 1.29 . There does not appear to be any obvious pattern in relation to the output locations, or any of the events showing more (or less) diversity. The average $\mathrm{CoV}$ is approximately 0.62. This says that on average, the standard deviation of the maximum amplitudes forecast for any particular event is likely to be about $62 \%$ of the mean value. This could certainly have the consequence that if tsunami threats are based on values of maximum amplitude in coastal regions, then different forecast centres may well be providing different threat levels for the same event.

\section{Discussion}


The aim of this paper is to provide a broad assessment of the diversity that may be expected in tsunami forecasts from a number of scenario databases. As mentioned previously, there are several factors that will contribute to the differences that are seen in the forecast maximum amplitudes. Among them are: initial conditions (source models); bathymetry dataset and its resolution; wave propagation physics (e.g., linear or nonlinear shallow water equations); numerical approximations; interpolation between or scaling of pre-computed scenarios according to magnitude. All these factors may contribute to the very different forecasts seen here. The underlying forecast uncertainties should be carefully analyzed and understood in order for there to be effective interoperability of the RTSPs. Further work (indicated in Section 7) will investigate these and some more specific factors. As an initial investigation, here we will consider just a few possible contributing factors.

\subsection{Length of time series}

We first examine the effect of the different lengths of time series that are provided. These have ranged from 10 hours to over 27 hours. It is worth examining this as for some cases, the maximum modelled amplitude occurs relatively late in the time series. As noted in Section 4, this is often observed in tsunami signals at tide gauges. Figure 5 shows one example of the full time series provided by each centre. It can be seen that maximum amplitude in some cases occurs well beyond 10 hours, so it is perhaps not appropriate to be comparing maximum amplitudes between one time series that is, for example, 10 hours long and another that is 24 hours long.

Maximum amplitudes were recomputed from the first 10 hours of each time series only. The $\mathrm{CoV}$ was again determined for each event and each output location and these results are shown in Figure 6. It can be seen that if the time series are limited to the same period of time (10 hours) then the $\mathrm{CoV}$ is considerably reduced. Indeed, the mean $\mathrm{CoV}$ is reduced from $62 \%$ to $54 \%$. We can therefore conclude that at least some part of the diversity in maximum amplitudes is due to the determination of maximum amplitudes over different periods of time.

\subsection{Depth at output location}


Table 3 shows that the defined output locations are at quite different depths according to each centre. This should have some effect on the modelled tsunami amplitudes as shoaling will occur in shallow waters. The different reported depths are a reflection of the different bathymetry data sets that are used within each system. In an attempt to assess the impact that this might have on the results, we use Greens Law (see Equation 1) to normalise all amplitudes to the same effective depth. The use of Greens Law is used here predominantly because within the Indian Ocean RTSP procedures, tsunami amplitude forecasts are expected to be provided at an equivalent $1 \mathrm{~m}$ depth. Many centres will use Greens Law to translate deep water tsunami amplitude values to $1 \mathrm{~m}$ where they do not have direct forecasts in the shallow water.

Based on the results of Section 5.1, in this section, the time series are limited to the first 10 hours only. Greens Law was applied to each maximum amplitude, using the depth values shown in Table 4 , to transform the amplitude values to an effective depth of $1 \mathrm{~m}$.

The results can be seen in Figure 7. A number of changes can be seen for individual locations but the mean $\mathrm{CoV}$ is reduced only very slightly from $54 \%$ to $53.5 \%$. This suggests that despite the large variability seen in the depths of the output locations, this is not a major factor in the overall diversity seen in the maximum amplitudes at these coastal locations. Of course, this does not mean that the different bathymetry datasets are not affecting other components of the tsunami propagation.

\section{Conclusions}

Since the 2004 Indian Ocean tsunami, there has been a significant increase in the effort put towards the development of real-time tsunami forecasting. We are currently in a position where there are several international centres that are able to provide real-time numerical tsunami predictions.

It has been shown here that when provided with earthquake details that are currently available in real time (geographical location, moment magnitude), there is likely to be considerable diversity in predicted tsunami amplitudes that are obtained from different forecast systems. On average, the standard deviation of the maximum amplitudes is approximately $62 \%$ of the mean value. It 
has further been shown that a significant portion of this diversity can be attributed to the different lengths of the scenario time series, and it appears that, at least at these coastal locations, variability in the bathymetry datasets is not likely to be a large contributor to the diversity.

This has implications for the interoperability of RTSPs in the Indian Ocean. For example, given that the length of the time series has some effect on forecast diversity, operational RTSPs should ensure that the maximum amplitudes that are exchanged are calculated from the same length of time series, particularly since tsunami threat assessments and warning decisions will be based on these values.

It could be argued that the variability seen in the forecasts is a reflection of the uncertainty surrounding real-time tsunami prediction, so it is not necessarily unrealistic. An individual NTWC receiving forecasts from a number of different RTSPs could formulate a warning strategy to take advantage of this. For example, they may elect to use the worst case forecast, or could adopt a consensus forecasting technique.

On the other hand, the aim of any forecasting centre is to provide a tsunami forecast that is as accurate as possible, and with a range of different forecasts such as has been presented here, it is necessarily the case that many, if not all of them will be inaccurate. Efforts should be made to evaluate the quality and reliability of existing forecast procedures, and beyond that, to improve tsunami forecast accuracy and thus reduce the diversity seen in multiple forecasts. Options for this include objective and quantitative use of deep water sea-level observations, such as are obtained from tsunameters and used, for example, within the SIFT system. One issue with this is that while the tsunameter network is extensive and robust within the Pacific Ocean, there is considerably less coverage within the Indian Ocean. At time of writing, there are only three tsunameters in the Indian Ocean that are functioning and have data available in real-time to operational centres for forecast and warning purposes.

Other options to improve tsunami forecast accuracy involve obtaining better information on the earthquake rupture in real-time. Effort is being directed towards the incorporation of data from seismic arrays and real-time GPS arrays (Sobolev et al. 2007) to provide information on rupture direction and slip distribution. Ideally these would be coupled to a tsunami model that could 
calculate the inundation or wave amplitudes in shallow-water in real-time. This would reduce the need for the scenario databases to try to incorporate "all" potential earthquakes

The variety of tsunami amplitudes shown here illustrates that just knowing the coordinates of the hypocentre and the magnitude is insufficient to completely constrain the tsunami amplitudes for warning purposes. High quality sea-level observations, or detailed knowledge of the crustal properties at the source, the bathymetry and the rupture also appear to be required.

\section{Further work}

This work has examined the diversity in 8 tsunami forecast systems that were available at time of writing. As further forecast systems are developed, these can (and should) also be considered. For example, the Pacific Tsunami Warning Center (PTWC) has recently developed an experimental real-time tsunami forecast model (RIFT; Wang et al., 2012) which could be included in further studies.

The aim of the present work has been to determine the extent to which tsunami amplitude forecasts might differ within an inter-operable tsunami forecast and warning system.. In this work, we have focused on differences that arise due to the numerical model based forecast systems, but there are a number of other relevant factors. For example, in real-time the earthquake details are not known precisely, and differences in the estimated earthquake magnitude or location will also contribute to diversity in the resulting tsunami forecasts. This uncertainty can be up to $0.3 \mathrm{M}_{\mathrm{w}}$ and on occasions, even larger (Allen and Greenslade, 2012). The impact of this is an important issue for real-time tsunami forecast and warning.

In this work, forecast diversity has been limited to those forecasts for which maximum amplitudes are above $1 \mathrm{~mm}$. While numerical models are quite capable of providing forecasts with this level of precision, it could be argued that assessing the diversity when the amplitudes are so small is not useful. Further work could focus on only the larger waveheights, which are close to RTSP tsunami threat assessment thresholds (currently $>0.5 \mathrm{~m}$ at $1 \mathrm{~m}$ depth unless otherwise specified). 
A standard deviation of more than $50 \%$ of the mean value is an indication of considerable variability and it would be useful and interesting to investigate the reasons behind this diversity in more detail. Figure 7 shows that there is a considerable range in the diversity, with some events and locations showing relatively low variability, and some cases showing high variability. It would interesting to investigate whether there are any factors, such as earthquake magnitude, directivity of the propagation, or distance between source and output location, for which more diversity would be expected.

Further work could focus on detailed analysis of the reasons behind the forecast diversity and could attempt to attribute the effects of different factors such as assumptions made about the earthquake rupture, variations in initial seafloor deformation, bathymetry, numerics, resolution, etc. An interface such as ComMIT (Titov et al., 2011) could be useful for this sort of activity as it allows a user to constrain certain factors (such as the earthquake source) while allowing exploration of different numerical models. Answering these questions would be a step towards more effective interoperability of the RTSPs.

An important issue for warning centres is the need to forecast tsunami arrival times in addition to amplitudes. This has been touched on briefly in Section 4 but not examined here in detail. This should be considered for further analysis.

\section{Acknowledgements}

The authors would like to thank Stewart Allen and three anonymous reviewers for their useful comments on the manuscript.

\section{References}

Allen, S. C. R. and D. J. M. Greenslade, 2012: Indices for the Objective Assessment of Tsunami Forecast Models, Pure. Appl. Geophys. Topical Volume, doi:10.1007/s00024-012-0522-4. Amante, C. and B. W. Eakins, 2009. ETOPO1 1 Arc-Minute Global Relief Model: Procedures, Data Sources and Analysis. NOAA Technical Memorandum NESDIS NGDC-24, 19 pp. Annunziato, A., 2007. The Tsunami Assessment Modelling System by the Joint Research Centre, Sci. Tsun. Haz., 26, no. 2., p70. 
Babeyko, A. Y., Hoechner, A., and Sobolev, S. V., 2010. Source modeling and inversion with near real-time GPS: a GITEWS perspective for Indonesia, Nat. Hazards Earth Syst. Sci. 10, 1617-1627, doi: 10.5194/nhess-10-1617-2010.

Bassin, C., Laske, G., and Masters, G., 2000. The current limits of resolution for surface wave tomography in North America, EOS Trans AGU, 81, F897, http://mahi.ucsd.edu/Gabi/rem.html.

Becker, J. J., D. T. Sandwell, W. H. F. Smith, J. Braud, B. Binder, J. Depner, D. Fabre, J. Factor, S. Ingalls, S-H. Kim, R. Ladner, K. Marks, S. Nelson, A. Pharaoh, R. Trimmer, J. Von Rosenberg, G. Wallace, P. Weatherall., 2009. Global Bathymetry and Elevation Data at 30 Arc Seconds Resolution: SRTM30_PLUS, Marine Geodesy, 32:4, pp 355-371.

Bilek, S. L. and Lay, T., 1999. Rigidity variations with depth along interplate megathrust faults in subduction zones, Nature 400, 443-446.

Bird, P., 2003. An updated digital model of plate boundaries, Geochemistry Geophysics Geosystems, 4(3), 1027, doi:10.1029/2001GC000252.

Burbidge, D.R., Cummins, P.R. Mleczko, R and H.K. Thio, 2008. A Probabilistic Tsunami Hazard Assessment for Western Australia, Pure and Appl. Geophys, 165, 2059 - 2088, DOI 10.1007/s00024-008-0421-X.

Cummins, PR. 2007. The potential for giant tsunamigenic earthquakes in the north Bay of Bengal, Nature, 449, DOI:10.1038/nature06088, 6 September 2007.

Geist, E.L., and R. Dmowska, 1999. Local tsunamis and distributed slip at the source, Pure Appl. Geophys., 154, 485-512.

Gica, E., Spillane, M.C., Chamberlin, C.D. and J.C. Newman, 2008. Development of the Forecast Propagation Database for NOAA's Short-term Inundation Forecast for Tsunamis (SIFT), NOAA Tech. Memo. OAR PMEL-139

González, F. I., Geist, E. L., Jaffe, B., Kanoglu, U., Mofjeld, H., Synolakis, C. E., Titov, V V., Arcas, D., Bellomo, D., Carlton, D., Horning, T., Johnson, J., Newman, J., Parsons, T., Peters, R., Peterson, C., Priest, G., Venturato, A., Weber, J., Wong, F., Yalciner, A., 2009, Probabilistic Tsunami Hazard Assessment at Seaside, Oregon for Near- and Far-field Seismic Sources," Journal of Geophysical Research-Ocean, 114, C11023.

Greenslade, D.J.M., Simanjuntak, M.A. and S.C.R. Allen, 2009. An Enhanced Tsunami Scenario Database:T2, CAWCR Technical Report No. 14., Bur. Met., Australia. 
Greenslade, D.J.M., S.C.R. Allen and M.A. Simanjutank, 2011. An Evaluation of Tsunami Forecasts from the T2 Scenario Database, Pure Appl. Geophys. Topical Volume, 168, No. 6-7 , pp 1137 - 1151, doi:10.1007/s00024-010-0229-3

Gudmundsson , O., and Sambridge, M. 1998. A regionalized upper mantle (RUM) seismic model, J. Geophys. Res. B4, 7121-7136.

Harig, S., Chaeroni, Pranowo, W. S., and J. Behrens, 2008. Tsunami simulations on several scales: Comparison of approaches with unstructured meshes and nested grids, Ocean Dyn., 58, 429-440, doi:10.1007/ s10236-008-0162-5.

Indian Ocean Tsunami Warning and Mitigation System (IOTWS), 2008, Implementation Plan for Regional Tsunami Watch Providers, IOC Information Series No. 81. UNESCO.

Indian Ocean Tsunami Warning and Mitigation System (IOTWS), 2009, Report of Intersessional Meeting of Working Group 5.

Imamura, F., 2006. TUNAMI-N2 (Tohoku University's Numerical Analysis Model for Investigation of Near Field Tsunamis version 2) Manual draft, http://www.tsunami.civil.tohoku.ac.jp/hokusai3/J/projects/manual-ver-3.1.pdf, accessed 16th Dec 2006.

IUGG/IOC TIME Project, 1997. Numerical method of tsunami Simulation with the leap-frog scheme, Intergovernmental Oceanographic Commission Manuals and Guides, Vol. 35.

Kopp, H., and Kukowski, N., 2003. Backstop geometry and accretionary mechanics of the Sunda margin, Tectonics, 22, 6, 1072, doi:10.1029/2002TC001420.

Mansbridge, J. Bathymetry comparisons, unpublished document, CSIRO.

Mansinha, L. and Smylie, D.E., 1971. The displacement fields of inclined faults, Bulletin of the Seismological Society of America, Vol. 61, no. 5, pp. 1433-1440.

Murthy, R.M.V., Sundramoorthy, S., Pari, Y., Rao, R.V., Mishra, P., Bhat, H., Tune, U., Venkatesan, R., and B.R. Subramanian, 2005. Inundation of sea water in Andaman and Nicobar Islands and parts of Tamil Nadu coast during 2004 Sumatra tsunami. Current Science, 88 (11), pp 1736-1740. ISSN 0011-3891

Nayak, S. and T. S. Kumar, 2008a. The First Tsunami Early Warning Centre in the Indian Ocean, Risk Wise, Tudor Rose Publications, pp 175-177.

Nayak, S. and T.S. Kumar, 2008b. Addressing the Risk of the Tsunami in the Indian Ocean, Journal of South Asia Disaster Studies, Vol. 1, No. 1, Page 45-57. 
Nayak, S. and T. S. Kumar, 2008c. Indian Tsunami Warning System, Proceedings of the ISPRS Technical Commission IV, Vol. XXXVII, 2008, Page 1501 - 1506.

Okada, Y., 1985. Surface deformation due to shear and tensile faults in a half- space. Bull. Seismol. Soc. Am., 75, 1135-1154.

Rabinovich, A.B. and R.E. Thomson, R.E., 2007. The 26 December 2004 Sumatra Tsunami: Analysis of Tide Gauge Data from the World Ocean Part 1. Indian Ocean and South Africa. Pur. and Appl. Geophys. 164, 261-308

Ruangrassamee, A. and Saelem, N. 2009. Effect of Tsunamis generated in the Manila Trench on the Gulf of Thailand, Journal of Asian Earth Sciences, 36, 56-66. doi:10.1016/j.jseaes.2008.12.004.

Satake, K., 1995. Linear and nonlinear computations of the 1992 Nicaragua earthquake tsunami, Pageoph, 144, 455-470

Simanjuntak, M.A., Greenslade, D.J.M. and S.C.R. Allen, 2011: Extensions to the T2 Tsunami Scenario Database, CAWCR Research Letters Issue 7, Bur. Met., Australia.

Sobolev, S. V., A. Y. Babeyko, R. Wang, A. Hoechner, R. Galas, M. Rothacher, D. V. Sein, J. Schröter, J. Lauterjung, and C. Subarya, 2007. Tsunami early warning using GPS-Shield arrays, J. Geophys. Res., 112, B08415, doi:10.1029/2006JB004640.

Synolakis, C. E., Bernard, E. N., Titov, V. V., Kanoglu, U., and González, F. "Validation and Verification of Tsunami Numerical Models," Pure and Applied Geophysics, 165(11-12), 2197-2228 (2008).

Tang, L., Titov, V. V., Bernard, E., Wei, Y., Chamberlin, C., Newman, J. C., Mofjeld, H., Arcas, D., Eble, M., Moore, C., Uslu, B., Pells, C., Spillane, M. C., Wright, L. M. \& Gica, E. (2012) Direct energy estimate of the 2011 Japan tsunami using deep-ocean pressure measurements. J. Geophys. Res.-Oceans. (doi:10.1029/2011JC007635)

Time project. 1997. IUGG/IOC Time Project: numerical method of tsunami simulation with the leap-frog scheme. IOC Manuals and Guides 35, pp. 126.

Thio, H.K., Somerville, P., Polet, J., and Ichinose, G. 2007. Application of Probabilistic Tsunami hazard Analysis to Ports and Harbors, Proceedings of "Ports 2007”, San Diego, March 25-28, organized by the American Society of Civil Engineers

Titov, V.V., 2009. Tsunami forecasting. Chapter 12 in The Sea, Volume 15: Tsunamis, Harvard University Press, Cambridge, MA and London, England, 371-400.

Titov, V.V., Moore, C., Greenslade, D.J.M., Pattiaratchi, C., Badal, R., Synolakis, C.E. and U. 
Kanoglu, 2011: A new tool for inundation mapping: Community Modeling Interface for Tsunamis (ComMIT), Pure Appl. Geophys. Topical Volume, doi: 10.1007/s00024-0110292-4

Titov, V.V. and C.E. Synolakis,1998. Numerical Modeling of Tidal Wave Runup, J. Waterw. Port Coast. Ocean Eng, 124(4), pp157 - 171.

Usha, T., Murthy, M.V.R., Reddy, N.T., and T. S. Murty, 2009. Vulnerability assessment of car nicobar to tsunami hazard using numerical model, Science of Tsunami Hazards, 2009, Vol. 28, No. 1, Page 15-34.

Wang, D., Becker, N.C., Walsh,D., Fryer, G.J., Weinstein, S.A., McCreery, C.S., Sardiña,V.S., Hsu,V., Hirshorn, B.F., Hayes, G.P., Duputel, Z., Rivera, L., Kanamori, H., Koyanagi, K.K, and B. Shiro 2012. Real-time forecasting of the April 11, 2012 Sumatra tsunami, Geophys. Res. Lett., 39, L19601, doi:10.1029/2012GL053081.

Wang, R., Lorenzo Martín, F., and F. Roth, 2003. Computation of deformation induced by earthquakes in a multi-layered elastic crust_FORTRAN programs EDGRN/EDCMP, Computers \& Geosciences, 29, 195-207.

Wang, R., Martin, F. L., and Roth, F. 2006. Computation of deformation induced by earthquakes in a multi-layered crust - FORTRAN programs EDGRN EDCMP, Comp. \& Geosc., 29, 195-207 (inc. erratum).

Wei, Y., Bernard, E. N., Tang, L., Weiss, R., Titov, V. V., Moore, C., Spillane, M., Hopkins, M., and Kanoglu, U. (2008), Real-time experimental forecast of the Peruvian tsunami of August 2007 for U.S. coastlines, Geo. Res. Let., 35, 1-7, doi:10.1029/2007GL032250.

Wells, D. L. and K.J. Coppersmith, 1994. New empirical relationships among magnitude, rupture length, rupture width, rupture area, and surface displacement, Bull. Seismol. Soc. Am., 84, 974-1002. 


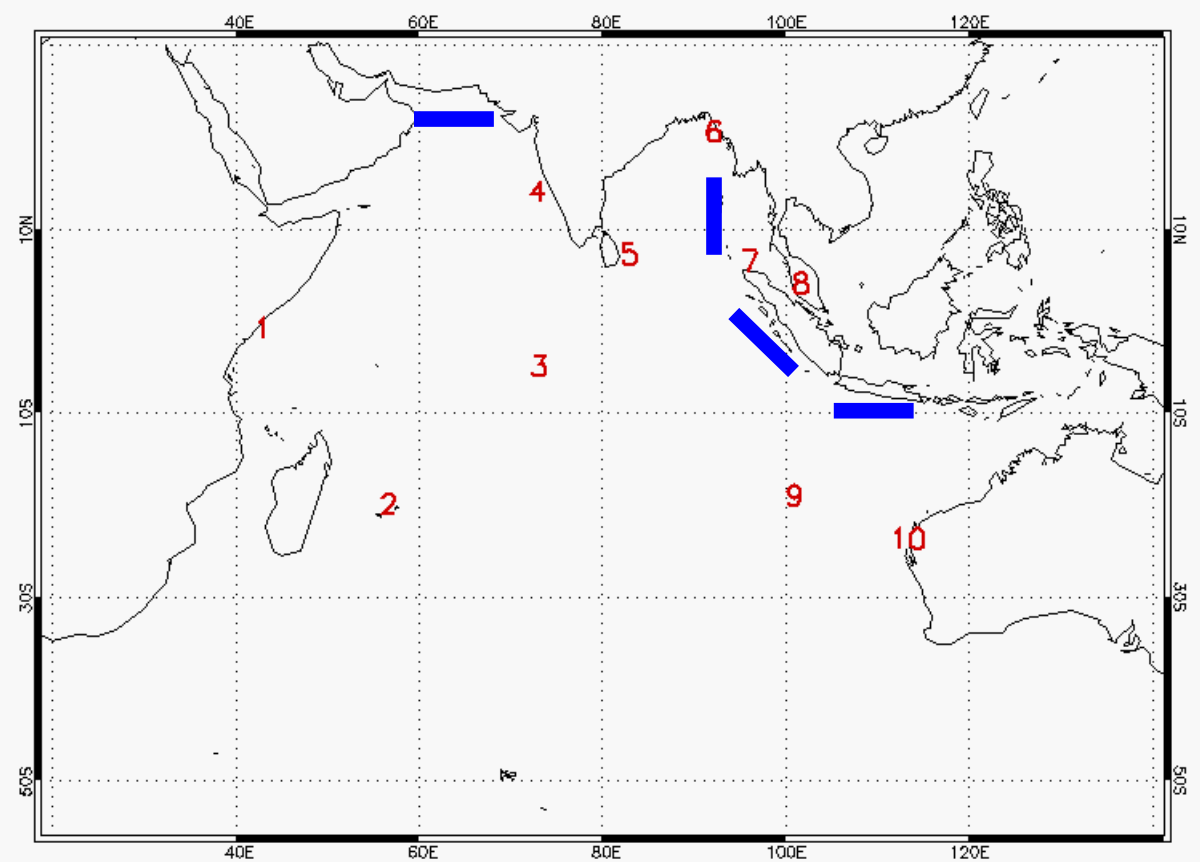

Figure 1 Approximate locations of the earthquake sources (blue lines) and output locations (red numbers). 

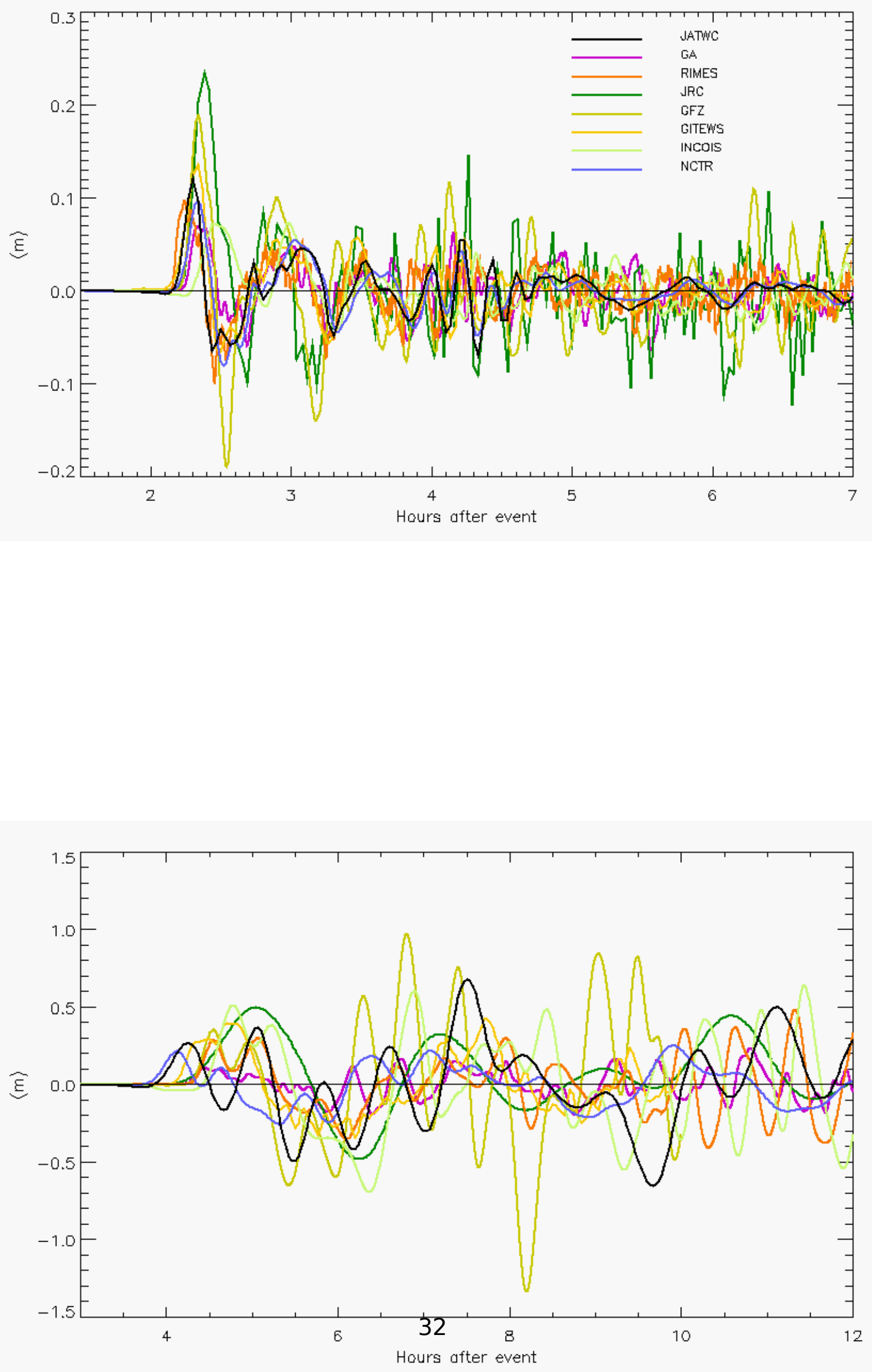
Figure 2 (a) Time series from all available centres for the Sunda South B scenario at Location 9. (b) Time series from all available centres for the Sunda Central B scenario at Location 10. 

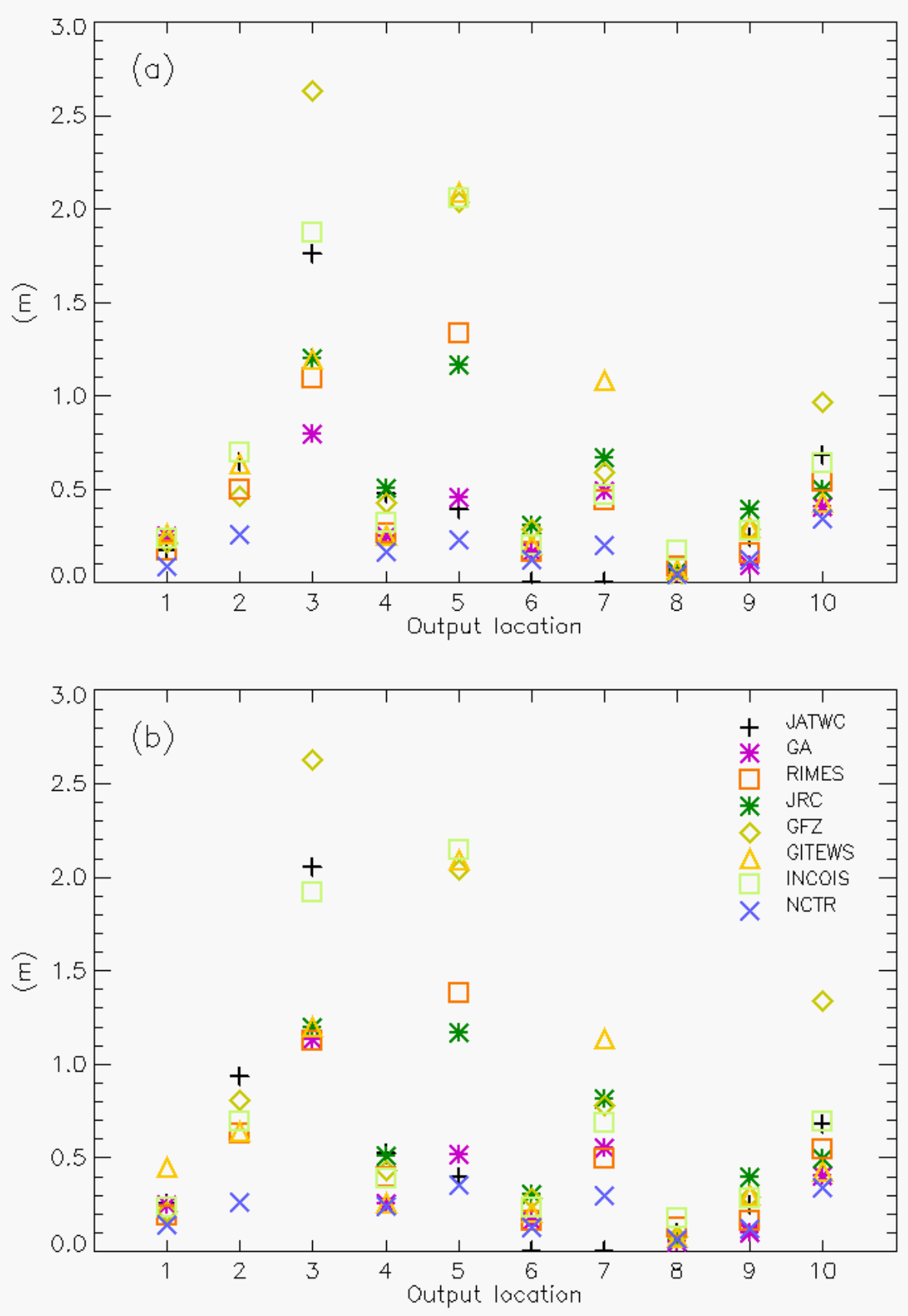

Figure 3. Raw maximum amplitudes at each location over entire time series for the Sunda Central B scenario. (a) Positive amplitudes only; (b) positive and negative amplitudes. 


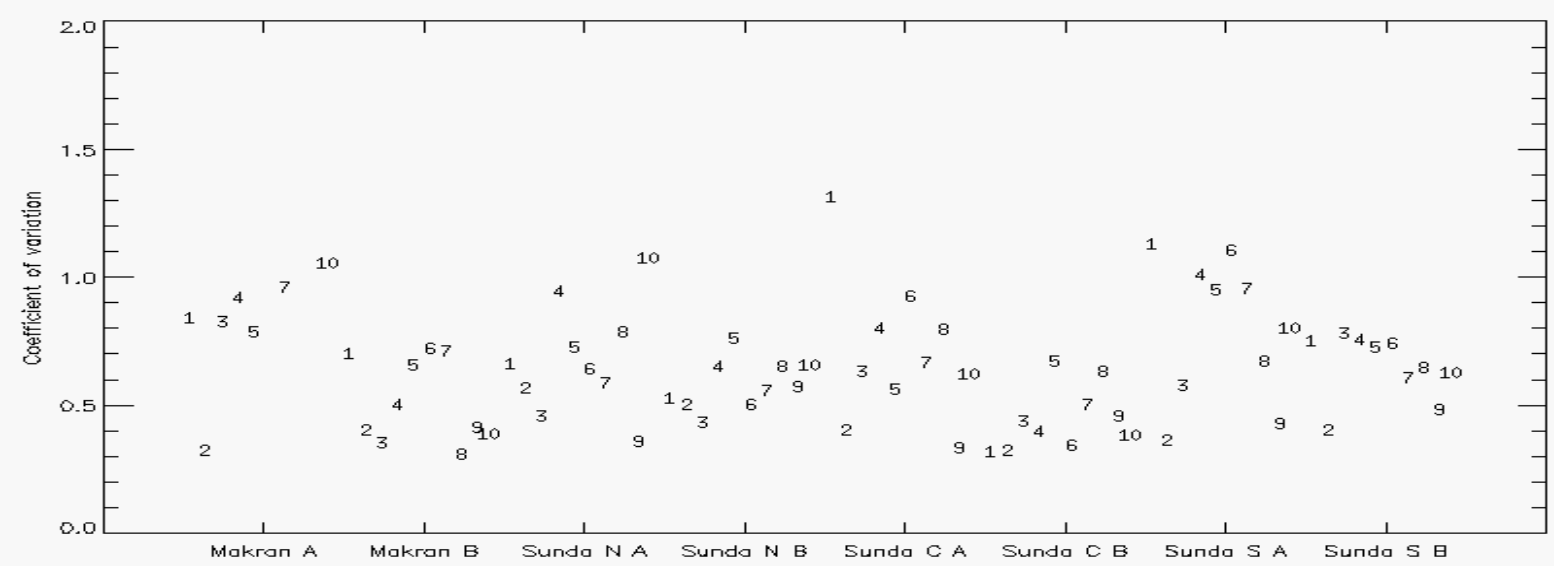

Figure 4 Coefficient of Variation (CoV) for the full time series for each hypothetical event and each output location. The numbers relate to the output location ( see Figure 1). 


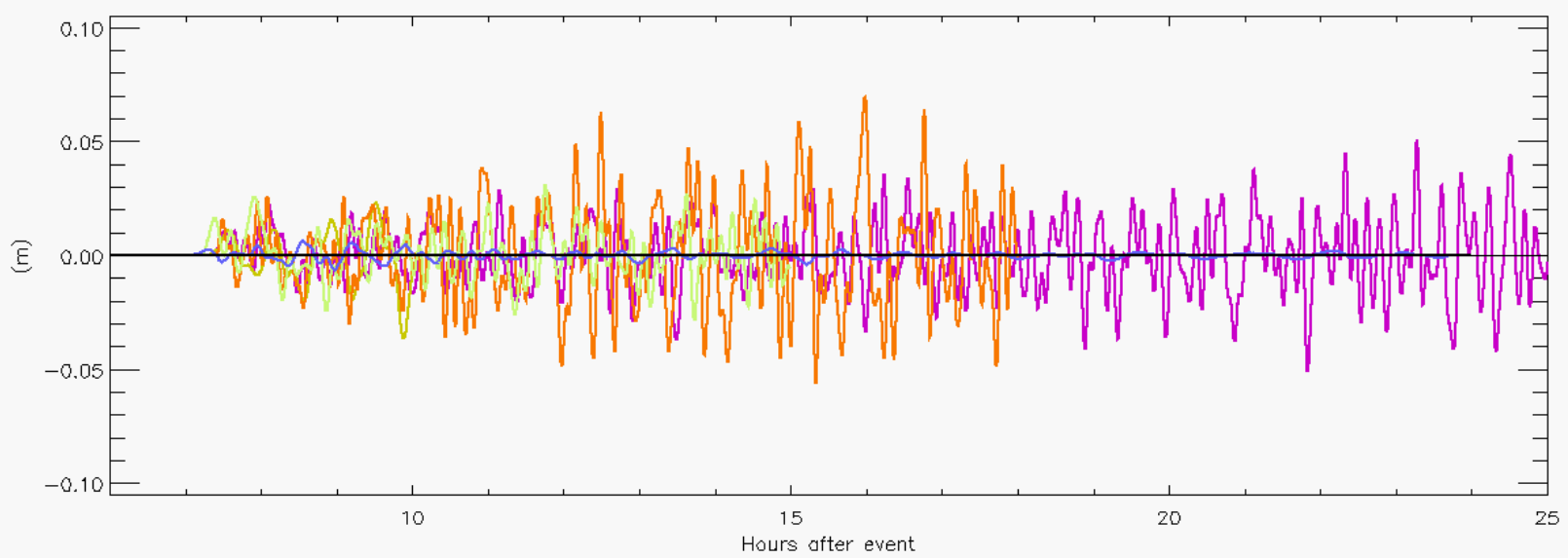

Figure 5. Time series from all available centres for the Makran A scenario at Location 6 for the entire time series provided by each centre. For legend, see Figure 2. 


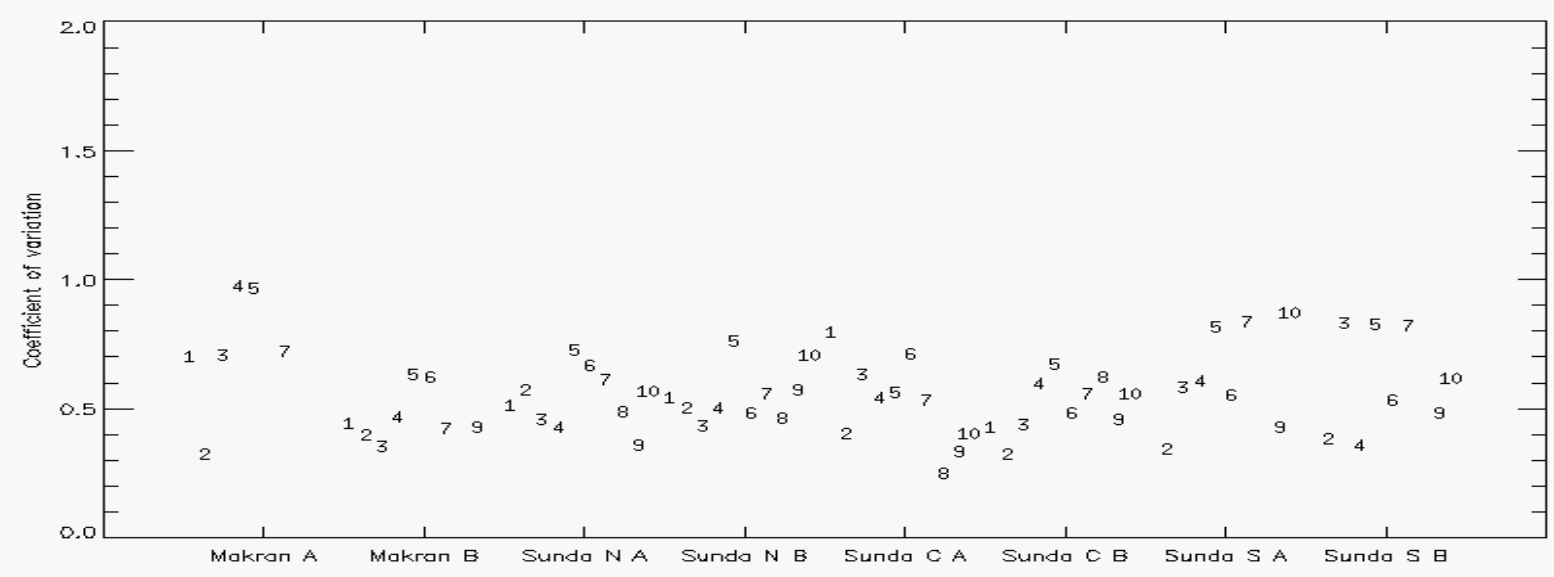

Figure 6 Same as Figure 4 but limited to the first 10 hours of each time series. 


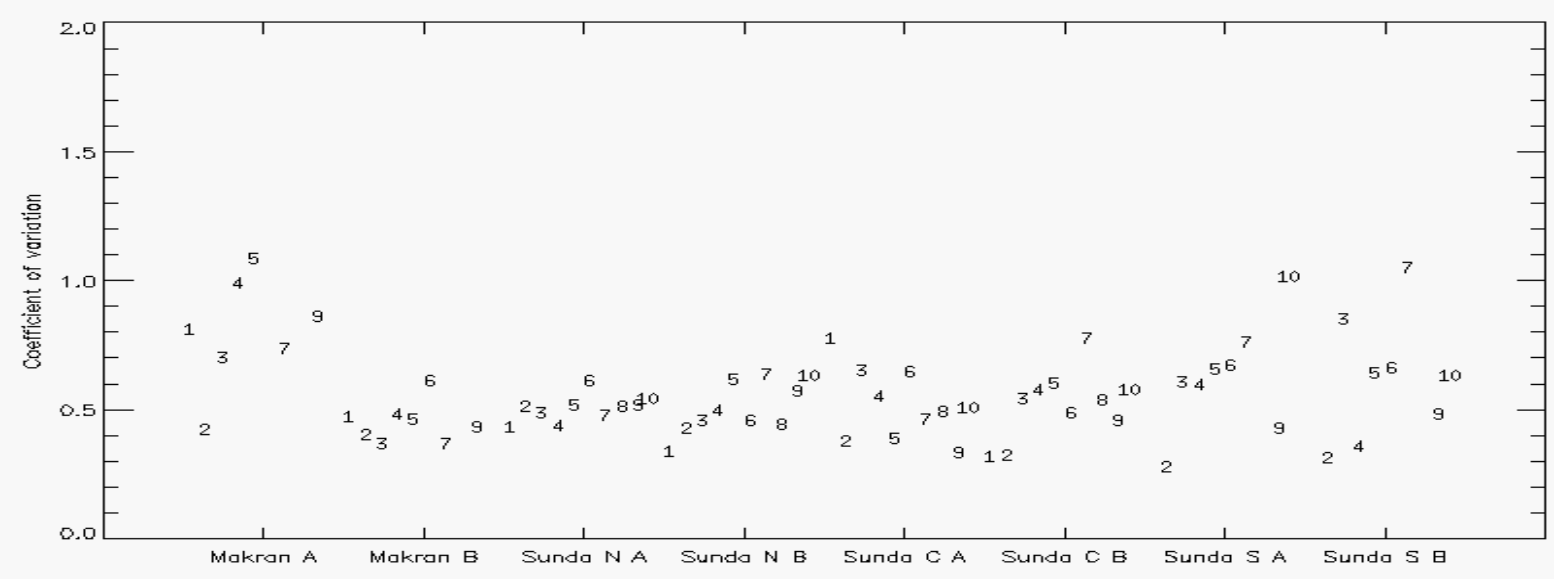

Figure 7 Same as Figure 4 but limited to the first 10 hours of each time series and with all maximum amplitudes transformed using Greens Law to an effective depth of $1 \mathrm{~m}$. 